\title{
Advanced Access scheduling in general practice and use of primary care: a Danish population-based matched cohort study
}

\section{Maria Bang ${ }^{1 *}$, Henrik Schou Pedersen1, Bodil Hammer Bech², Claus Høstrup Vestergaard ${ }^{1}$, Jannik Falhof', Hans Christian Kjeldsen', Peter Vedsted ${ }^{1}$, Mogens Vestergaard ${ }^{1}$}

${ }^{1}$ Reseach Unit for General Practice, Aarhus, Denmark; ${ }^{2}$ Department of Public Health, Aarhus University, Aarhus, Denmark

\begin{abstract}
Background: Advanced access scheduling (AAS) allows patients to receive care from their GP at the time chosen by the patient. AAS has shown to increase the accessibility to general practice, but little is known about how AAS implementation affects the use of in-hours and out-of-hours (OOH) services.

Aim: To describe the impact of AAS on the use of in-hours and $\mathrm{OOH}$ services in primary care.

Design \& setting: A population-based matched cohort study using Danish register data.

Method: A total of 161901 patients listed in 33 general practices with AAS were matched with 287 837 reference patients listed in 66 reference practices without AAS. Outcomes of interest were use of daytime face-to-face consultations, and use of $\mathrm{OOH}$ face-to-face and phone consultations in a 2-year period preceding and following AAS implementation.

Results: No significant differences were seen between AAS practices and reference practices. During the year following AAS implementation, the number of daytime face-to-face consultations was $3 \%$ (adjusted incidence rate ratio $[$ alRR $]=1.03 ; 95 \%$ confidence interval $[\mathrm{Cl}]=0.99$ to 1.07 ) higher in the AAS practices compared with the number in the reference practices. Patients listed with an AAS practice had $2 \%$ (aIRR $=0.98 ; 95 \% \mathrm{Cl}=0.92$ to 1.04 ) fewer $\mathrm{OOH}$ phone consultations and $6 \%$ (aIRR $=0.94 ; 95 \% \mathrm{Cl}=0.86$ to 1.02 ) fewer $\mathrm{OOH}$ face-to-face consultations compared with patients listed with a reference practice.
\end{abstract}

*For correspondence: mariabang91@gmail.com

Competing interest: The authors declare that no competing interests exist.

Received: 24 March 2020 Accepted: 26 March 2020

Published: 04 November 2020

(C)This article is Open Access: CC BY license (https://creativecommons.org/licenses/by/4.0/)

Author Keywords: primary health care, general practice, after-hours care, health services accessibility, Denmark

Copyright (C) 2020, The Authors; DOI:10.3399/

bjgpopen20X101091
Conclusion: This study showed no significant differences following AAS implementation. However, a trend was seen towards slightly higher use of daytime primary care and lower use of $\mathrm{OOH}$ primary care.

\section{How this fits in}

AAS is intended to improve the access to primary care. This population-based cohort study is the first to explore how AAS affects the use of in-hours and $\mathrm{OOH}$ primary care. The presented results indicate no significant changes in the healthcare utilisation following AAS implementation. However, a trend was seen towards slightly higher use of daytime primary care and lower use of $\mathrm{OOH}$ primary care. The influence of AAS on the use of primary care should be further explored in future studies.

\section{Introduction}

Accessibility and continuity of care are two cardinal goals of primary care. Many GPs struggle to achieve these goals owing to an increasing number of patient visits. ${ }^{1-3}$ Reduced access to daytime 
primary care can lead to worse health outcomes as well as physical and emotional stress in the patient. ${ }^{4}$ Moreover, the patients may choose to contact the $\mathrm{OOH}$ services or emergency departments (ED). ${ }^{5-8}$

To increase accessibility and ensure continuity of care, many GPs have introduced AAS. ${ }^{9}$ AAS is based on the principle that the patient can choose the date to be seen by the GP. ${ }^{10}$ Traditional scheduling systems are based on advance booking of appointments, where only a little time is reserved for urgent care. ${ }^{11}$ AAS requires no distinction between urgent and routine care, and patient preferences determine when appointments take place. ${ }^{12}$ Six key elements of AAS are important for successful application: balancing supply and demand; reducing backlog; reducing the variety of appointment types; developing contingency plans for unusual circumstances; adjusting demand profiles; and increasing 'bottleneck' resources. ${ }^{1}$ AAS has been shown to increase the accessibility of primary care, ${ }^{4,13,14}$ to reduce no-shows, to increase patient and provider satisfaction, and to ensure continuity of care. ${ }^{15-18}$

The effect of AAS on healthcare utilisation is still inconclusive, especially the effect on the use of $\mathrm{OOH}$ services. Solberg et al found that the use of daytime primary care increased following implementation of AAS, while the use of urgent care decreased significantly. ${ }^{19}$ Hudec et al found a significant drop in ED visits following AAS implementation, ${ }^{16}$ while Subramanian et al found no such correlation. ${ }^{20}$

The present study aimed to describe the impact of AAS on the use of daytime and OOH primary care in the year preceding and following AAS implementation in a number of Danish general practices, compared with a reference group of practices without AAS. It was hypothesised that the increased accessibility through AAS during office hours would cause higher use of daytime primary care and lower use of $\mathrm{OOH}$ primary care.

\section{Method}

\section{Study design}

A population-based matched cohort study was conducted, including patients listed with a general practice with AAS and their matched patients listed with a practice without AAS. Background information about the study population and their healthcare utilisation was extracted from Danish registers. This information was linked at a personal level through the unique personal identification number (PIN), which is assigned to all Danish citizens at birth or immigration. ${ }^{21}$

\section{Study population}

An internet search identified general practices using AAS according to their website $(n=48)$. Practices in the Capital Region of Denmark $(n=10)$ were not included owing to missing $\mathrm{OOH}$ data for this region in the Danish National Health Service Register (NHSR), ${ }^{22}$ leaving 38 practices to be invited. Thirty-three practices with AAS consented to participate in the study. Each included AAS practice was matched with two reference practices without AAS. The reference practices were identified in the Patient List Database ${ }^{23}$ based on municipality and number of listed patients. The date of AAS implementation was defined as the index date for the AAS practice and the two matched reference practices.

Most of the Danish population (98\%) is listed with a specific general practice, which must be consulted for medical advice. ${ }^{21}$ All patients listed with a participating AAS practice or reference practice at the index date were included in the study. A total of 449738 patients were included, of whom 161901 were listed with an AAS practice. The cohort was followed until death, emigration, change of GP, or the end of study (that is, 1 year following the index date or 30 June 2018), whichever came first.

\section{Exposure}

All participating AAS practices were initially interviewed. A brief questionnaire was used to verify their use of AAS and confirm the index date. The data were collected from 1 January 2018-31 March 2018 by phone or email, depending on the preference of the practice. Anonymous data extracted from the Patient List Database were used to identify the reference practices, and the staff in these practices were not interviewed. 


\section{Outcome}

Contacts to in-hours and $\mathrm{OOH}$ primary care in the year preceding and following the index date were applied as outcome measures. This included daytime face-to-face consultations, $\mathrm{OOH}$ face-to-face consultations, and $\mathrm{OOH}$ phone consultations. Information on all services provided in general practice was obtained from the NHSR ${ }^{22}$ (see Supplementary Appendix S1).

\section{Covariates}

The Danish Civil Registration System $(\mathrm{CRS})^{21}$ contained updated information about the patient's sex, age, and vital status. Statistics Denmark ${ }^{24}$ provided information about migration, ethnic group (Danish, immigrants, and descendants of immigrants), cohabitation status (cohabiting, living alone, children living at home, and children not living at home), family income, and highest attained education level ( $\leq 10$ years, $11-15$ years, and $\geq 16$ years). Information about calendar time was obtained from the index date identified from the questionnaires. The Charlson Comorbidity Index (CCl) was used to adjust for a range of comorbid conditions. ${ }^{25}$ Information about these conditions was obtained from the Danish National Patient Registry (DNPR) ${ }^{26}$ and the Danish Cancer Registry. ${ }^{27}$

\section{Statistical analysis}

All data were analysed using both unadjusted and adjusted negative binomial regression models with cluster-robust variance estimation at practice level. These models yielded incidence rate ratios (IRRs) and 95\% Cls with negative binomial distribution. The outcomes were analysed in pre-specified time periods around the index date. In the main analyses, consultations conducted in the entire year preceding and following the index date were included. The year following the implementation of AAS was subsequently divided into 3-month periods to explore if the use of healthcare services varied throughout the year. In the adjusted models, sex, age, calendar time, month of year, ethnic group, cohabitation status, family income, highest attained education level, and $\mathrm{CCl}$ were adjusted for. All covariates were measured at the index date.

\section{Results}

A total of thirty-three general practices with AAS were included in this study and matched with 66 reference practices. The study included 449738 patients, of whom 161901 (36\%) were listed with an AAS practice (Table 1). The differences between the two groups were small, although the patients listed with an AAS practice were more often men, less educated, had lower income, and were more often immigrants or descendants of immigrants compared with patients from the reference practices (Table 1).

Following AAS implementation, the patients listed in an AAS practice had slightly more face-toface consultations compared with the references, although the difference did not reach statistical significance (figure 1, upper part). The adjusted incidence rate ratio (alRR) was $1.03(95 \% \mathrm{Cl}=0.99$ to 1.07) in the year following AAS implementation. No difference was seen in the alRR when the year was divided into 3-month intervals Figure 1, lower part). In the year preceding ASS implementation, the alRR was $1.01(95 \% \mathrm{Cl}=0.96$ to 1.05$)$ when the patients listed in an AAS practice were compared with the references.

The patients listed in an AAS practice had fewer $\mathrm{OOH}$ consultations than the references (Figure 2, lower part), but these results were not statistically significant. In the year following AAS implementation, the alRR was $0.98(95 \% \mathrm{Cl}=0.918$ to 1.041$)$ for phone consultations and $0.94(95 \%$ $\mathrm{Cl}=0.863$ to 1.021 ) for face-to-face consultations when the AAS patients were compared with the references. When dividing the year into 3-month intervals, no difference between the periods was found (Figure 2, lower part). In the year preceding AAS implementation, the alRR was $1.00(95 \% \mathrm{Cl}=$ 0.93 to 1.06$)$ for phone consultations and $0.95(95 \% \mathrm{Cl}=0.87$ to 1.04$)$ for face-to-face consultations when the AAS patients were compared with the references (Figure 2, upper part).

\section{Discussion}

\section{Summary}


Table 1 Characteristics of study population at index date

\begin{tabular}{|c|c|c|}
\hline & Patients in AAS practices, $n(\%)$ & Patients in references practices, $\mathbf{n}(\%)$ \\
\hline$N(\%)$ & $161901(36.0)$ & $287837(64.0)$ \\
\hline Clinic size, mean (SD) & $4906(1902.2)$ & $4361(1606.0)$ \\
\hline Mean age, years (SD) & $41.52(23.49)$ & $41.76(23.54)$ \\
\hline \multicolumn{3}{|l|}{ Sex } \\
\hline Male & $82671(51.1)$ & $145101(50.4)$ \\
\hline Female & 79230 (48.9) & $142736(49.6)$ \\
\hline \multicolumn{3}{|l|}{ Education level } \\
\hline$\leq 10$ years & $46178(28.5)$ & $80727(28.1)$ \\
\hline$>10$ and $\leq 15$ years & $61117(37.8)$ & $109013(37.9)$ \\
\hline$>15$ years & $25825(16.0)$ & $46523(16.2)$ \\
\hline Unknown & $28781(17.7)$ & 51575 (17.8) \\
\hline \multicolumn{3}{|l|}{ Cohabitation status } \\
\hline Cohabiting & $80398(49.7)$ & $142777(49.6)$ \\
\hline Living alone & 34067 (21.0) & $61032(21.2)$ \\
\hline Children living at home & 32078 (19.8) & 57327 (19.9) \\
\hline Children not living at home & $15358(9.5)$ & $26701(9.3)$ \\
\hline \multicolumn{3}{|l|}{ Family income } \\
\hline Low & $55095(34.0)$ & $93870(32.6)$ \\
\hline Medium & $54032(33.4)$ & 95464 (33.2) \\
\hline High & $52774(32.6)$ & $98503(34.2)$ \\
\hline \multicolumn{3}{|l|}{ Ethnic group } \\
\hline Danish & $146473(90.5)$ & $262050(91.0)$ \\
\hline Immigrant & $12146(7.5)$ & $20485(7.1)$ \\
\hline Descendants of immigrants & $3282(2.0)$ & $5302(1.9)$ \\
\hline \multicolumn{3}{|l|}{ Calendar time } \\
\hline January 2011-December 2015 & $54282(33.5)$ & $98532(34.2)$ \\
\hline January 2016-December 2016 & $61822(38.2)$ & $106132(36.9)$ \\
\hline January 2017-December 2017 & $45797(28.3)$ & $83173(28.9)$ \\
\hline \multicolumn{3}{|l|}{ Number of chronic conditions } \\
\hline 0 & $127580(78.8)$ & $226628(78.7)$ \\
\hline $1-2$ & $27787(17.2)$ & $49416(17.2)$ \\
\hline$\geq 3$ & $6534(4.0)$ & $11793(4.1)$ \\
\hline
\end{tabular}

AAS $=$ advanced access scheduling. $S D=$ standard deviation.

In this large population-based cohort study, it was found that the patients listed with an AAS practice consulted their GP slightly more during the daytime and requested slightly fewer $\mathrm{OOH}$ services following the implementation of AAS compared with the references. However, the findings were not statistically significant.

\section{Strengths and limitations}

To the authors' knowledge, this is the largest study to evaluate AAS and the association with use of daytime and $\mathrm{OOH}$ primary care. Previous studies comprised only up to six AAS practices, ${ }^{14,16,20}$ were 


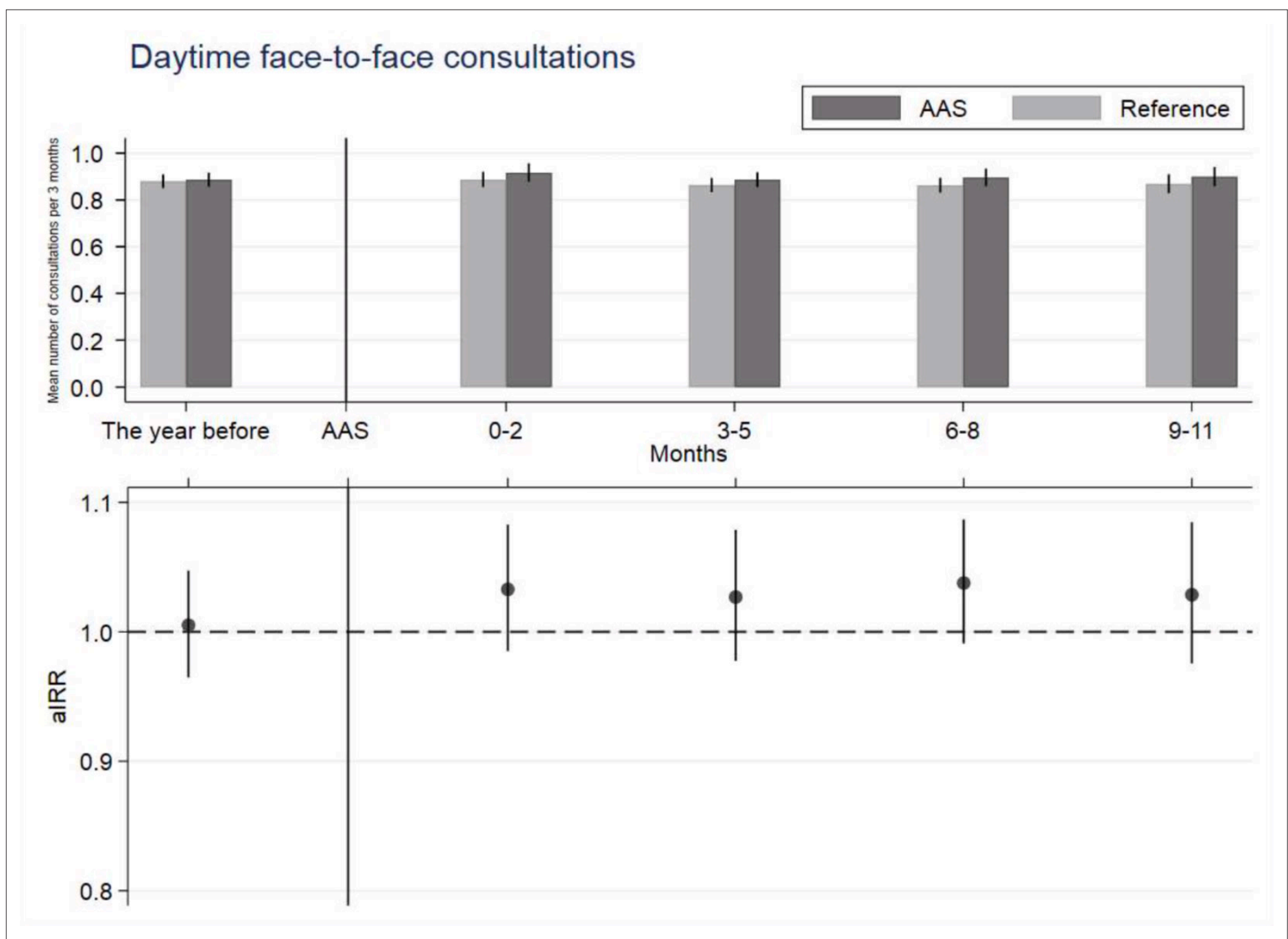

Figure 1 Daytime face-to-face consultations in general practice 1 year before and 1 year after the index date. The vertical line marks the index date. Upper part: mean number of consultations per patient per 3 months with 95\% confidence intervals (Cls) for patients listed with advanced access scheduling (AAS) practices and reference practices. Lower part: adjusted incident rate ratios (alRRs) with 95\% Cls adjusted for sex, age, vital status, ethnic group, cohabitation status, family income, highest-achieved education level, Charlson Comorbidity Index, calendar time, and month; all measured at the index date. 


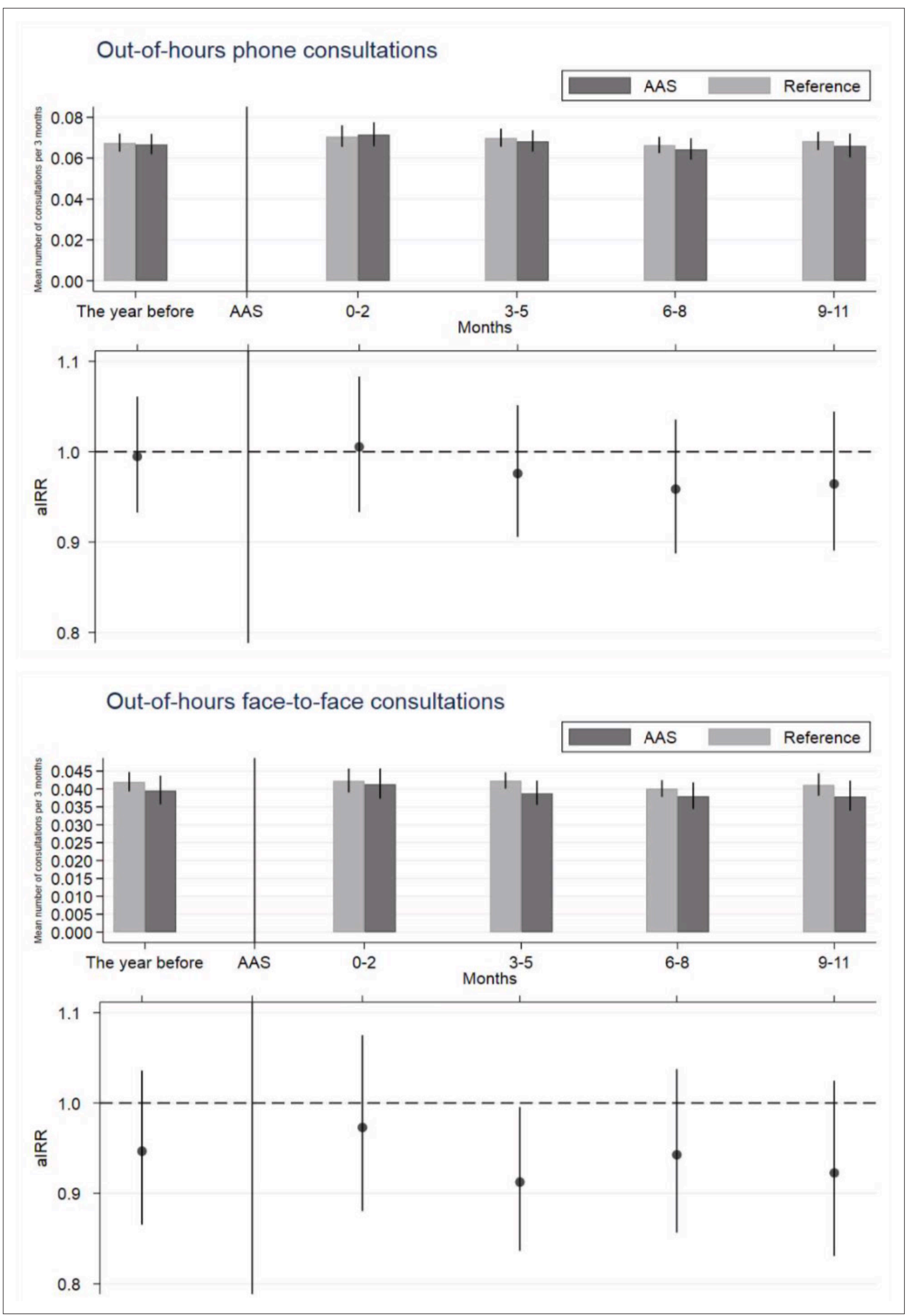

Figure 2 Out-of-hours face-to-face and phone consultations 1 year before and 1 year after the index date. The vertical line marks the index date. Upper part: mean number of consultations per patient per 3 months with 95\% confidence intervals (Cls) for patients listed with advanced access scheduling (AAS) practices and reference practices. Lower part: adjusted incident rate ratios (alRRs) with 95\% Cls adjusted for sex, age, vital status, ethnic group, cohabitation status, family income, highest-achieved education level, Charlson Comorbidity Index, calendar time, and month; all measured at the index date. 
implementation, or that the index date is imprecise because AAS was implemented over a period of time rather than on an exact date. Anonymous data extracted from the Patient List Database was used to identify the reference practices. The reference practice staff was not interviewed, and it cannot be excluded that some of the reference practices might have used a scheduling system ensuring equally high accessibility as the AAS system, which could have caused the results to underestimate the true effect of AAS.

In the analyses, adjustments were made for relevant covariates based on information from the $\mathrm{CRS}_{,}{ }^{21}$ Statistics Denmark, ${ }^{24}$ the DNPR, ${ }^{26}$ and the Danish Cancer Registry, ${ }^{27}$ and the index date was based on questionnaire responses. This approach was taken to reduce the risk of confounding from unmeasured factors, but the risk of residual confounding cannot be excluded. The study did not adjust for information about type of practice, and the number of working doctors and nurses was not included in the adjustment since the authors did not have this information. This could have affected the result if major differences existed between the AAS practices and the reference practices. The data on healthcare utilisation was obtained from electronic records in the NHSR, and this data did not rely on the memory of the GPs or the patients. The NHSR registrations of contacts to the GPs ${ }^{22}$ are considered highly valid as the GPs are reimbursed on the basis of these registrations following validation by the Danish regions. The authors see no reason why the quality of the healthcare utilisation registrations should be different between AAS practices and reference practices. Therefore, misclassification is likely to be non-differential, which tends to bias the study results towards the null hypothesis.

\section{Comparison with existing literature}

Some studies have shown that the implementation of AAS increases the use of daytime primary care ${ }^{19,27}$ and healthcare expenses. ${ }^{16}$ In keeping with previous studies, the results showed higher numbers of daytime consultations following AAS implementation. ${ }^{28}$ It was expected that the number of daytime face-to-face consultations would increase even more, especially in the period immediately following the implementation. However, this was not the case. In line with expectations, the study found a small reduction in the use of $\mathrm{OOH}$ services. Converted to absolute numbers, the patients listed with an AAS practice had 2716 fewer $\mathrm{OOH}$ face-to-face consultations and 1657 fewer $\mathrm{OOH}$ phone consultations compared with the references in the year following AAS implementation.

This study was the first to evaluate the use of $\mathrm{OOH}$ services following AAS implementation. Other studies have found a reduction in the use of $\mathrm{EDs}^{16}$ and urgent care clinics. ${ }^{19}$ However, these studies are not directly comparable to the present study as they had different outcomes and were conducted in countries with a different healthcare system to the Danish system. The results of the present study can be generalised to other countries with a healthcare system comparable to the Danish. ${ }^{29}$ However, the results might have been different if the study had been conducted in a country without free and equal access to health care.

A meta-analysis from 2017 found that AAS implementation reduced the waiting time for a primary care appointment by 11.3 days. ${ }^{4}$ Limited access to daytime primary care has previously been associated with higher use of EDs and $\mathrm{OOH}$ services. ${ }^{5-7,29,30}$ Moreover, studies have shown that patients experiencing difficulty with getting an appointment with their GP tend to use EDs and $\mathrm{OOH}$ services instead. ${ }^{6,7,30}$ Zhoe et al estimated that the use of $\mathrm{OOH}$ services can be reduced by $11 \%$ if the access to daytime primary care is optimal. ${ }^{5}$ Other studies have triaged the contacts to EDs and $\mathrm{OOH}$ services according to urgency, and found that it should be possible to reduce the number of non-urgent contacts by ensuring better access to daytime primary care. ${ }^{6,31}$ Unfortunately, the data did not include sufficient information to make a division between urgent and non-urgent contacts to the $\mathrm{OOH}$ services.

AAS implementation has been shown to be difficult in some practices. A large study set in England found that only 161 AAS practices - and less than half of the practices claiming to operate AAS used all the key principles of the AAS model. ${ }^{1,32}$ Other studies have shown that AAS implementation was very difficult and that the desired benefits from the AAS system were not obtained. ${ }^{33-35}$ Factors such as patient-provider satisfaction ${ }^{16-18,27}$ and continuity of care ${ }^{36-38}$ have shown to vary following AAS implementation. A large-scale study conducted in 47 general practices in the UK found that a $10 \%$ increase in the proportion of AAS appointments was associated with an $8 \%$ decrease in patient satisfaction. $^{39}$ 
AAS appointments have been found to be preferred by younger patients, whereas older patients seem to favour pre-booked appointments with their usual GP, especially in case of chronic disease checks. ${ }^{13,37,39}$ The right balance between demand and supply of appointments seems to be key when meeting the patient's needs for access to care and continuity in care. ${ }^{35,40}$ In the present study, the access to primary care was investigated as an organisational concept, whereas other aspects of access to health care were not investigated. Access to a healthcare system is a multidimensional construct, and patients' individual characteristics are known to affect their healthcare-seeking behaviour. ${ }^{41,42}$

\section{Implications for research and practice}

This study is the first to investigate the influence of AAS implementation on the use of primary care in Denmark. The findings present new knowledge to clinicians and may be generalisable to comparable countries with universal access to health care. Further research is needed to explore whether AAS implementation may influence the use of specific types of contacts to the $\mathrm{OOH}$ services, such as nonurgent contacts.

\section{Funding}

This work was supported by the Programme for Clinical Research Infrastructure (PROCRIN), which was established by the Lundbeck Foundation and the Novo Nordisk Foundation and administered by Danish Regions.

\section{Ethical approval}

The Danish Data Protection Agency (2009-41-3471) and the Committee of Multipractice Studies in General Practice (MPU 04-2018) approved this study. All data were anonymised and analysed at Statistics Denmark (project number: 706965).

\section{Provenance}

Freely submitted; externally peer reviewed.

\section{References}

1. Murray M, Berwick DM. Advanced access: reducing waiting and delays in primary care. JAMA 2003; 289(8): 1035-1040. DOI: https://doi.org/10.1001/jama.289.8.1035

2. Fisker J, Christiansen L, Christensen B. [The role of general practice in the future healthcare system] Almen praksis' rolle $i$ fremtidens sundhedsvæsen (in Danish). 2008; https://sum.dk/Aktuelt/Publikationer/ /media/Filer\%20-\% 20Publikationer_i_pdf/2008/Almen\%20praksis\%20rolle\%20i\%20fremtidens\%20sundhedsvsen.ashx (accessed 14 Jul 2020).

3. Danish Medical Association. [DMA analysis: increasing number of contacts and consultations in general practice] PLO Analyse: Stigende antal kontakter og konsultationer i almen praksis (in Danish). Copenhagen: DMA; 2017.

4. Ansell D, Crispo JAG, Simard B, Bjerre LM. Interventions to reduce wait times for primary care appointments: a systematic review. BMC Health Serv Res 2017; 17(1): 295. DOI: https://doi.org/10.1186/s12913-017-2219-y

5. Zhou Y, Abel G, Warren F, et al. Do difficulties in accessing in-hours primary care predict higher use of out-of-hours GP services? Evidence from an English national patient survey. Emerg Med J 2015; 32(5): 373-378. DOI: https:// doi.org/10.1136/emermed-2013-203451

6. Durand A-C, Palazzolo S, Tanti-Hardouin N, et al. Nonurgent patients in emergency departments: rational or irresponsible consumers? Perceptions of professionals and patients. BMC Res Notes 2012; 5(1): 525. DOI: https:// doi.org/10.1186/1756-0500-5-525

7. MacKichan F, Brangan E, Wye L, et al. Why do patients seek primary medical care in emergency departments? An ethnographic exploration of access to general practice. BMJ Open 2017; 7(4): e013816. DOI: https://doi.org/10. 1136/bmjopen-2016-013816

8. Rust G, Ye J, Baltrus P. Practical barriers to timely primary care access. Arch Intern Med 2008; 168(15): 1705-1710. DOI: https://doi.org/10.1001/archinte.168.15.1705

9. Fischer NF. [Several GPs introduce same-day booking] Flere praktiserende læger indfører booking af tid samme dag (in Danish). 2017; https://dagensmedicin.dk/flere-praktiserende-laeger-indfoerer-booking-tid-samme-dag/ (accessed 14 Jul 2020).

10. Murray M, Tantau C. Same-Day appointments: exploding the access paradigm. Fam Pract Manag 2000; 7(8): 45-50.

11. Fournier J, Heale R, Rietze LL. I can't wait: advanced access decreases wait times in primary healthcare. Healthc $Q$ 2012; 15(1): 64-68. DOI: https://doi.org/10.12927/hcq.2012.22763

12. Tantau C. Accessing patient-centered care using the advanced access model. J Ambul Care Manage 2009; 32(1): 32-43. DOI: https://doi.org/10.1097/01.JAC.0000343122.15467.48 
13. Salisbury $\mathrm{C}$, Goodall $\mathrm{S}$, Montgomery AA, et al. Does advanced access improve access to primary health care? Questionnaire survey of patients. Br J Gen Pract 2007; 57(541): 615-621.

14. Rohrer JE, Bernard M, Naessens J, et al. Impact of open-access scheduling on realized access. Health Serv Manage Res 2007; 20(2): 134-139. DOI: https://doi.org/10.1258/095148407780744679

15. Bundy DG, Randolph GD, Murray M, et al. Open access in primary care: results of a North Carolina pilot project. Pediatrics 2005; 116(1): 82-87. DOI: https://doi.org/10.1542/peds.2004-2573

16. Hudec JC, MacDougall S, Rankin E. Advanced access appointments: effects on family physician satisfaction, physicians' office income, and emergency department use. Can Fam Physician 2010; 56(10): e361-367.

17. Richter JP, Downs $L$, Beauvais B, et al. Does the proportion of same-day and 24-hour appointments impact patient satisfaction? Qual Manag Health Care 2017; 26(1): 22-28. DOI: https://doi.org/10.1097/QMH. 0000000000000121

18. Tuli SY, Thompson LA, Ryan KA, et al. Improving quality and patient satisfaction in a pediatric resident continuity clinic through advanced access scheduling. J Grad Med Educ 2010; 2(2): 215-221. DOI: https://doi.org/10.4300/ JGME-D-09-00087.1

19. Solberg LI, Maciosek MV, Sperl-Hillen JM, et al. Does improved access to care affect utilization and costs for patients with chronic conditions? Am J Manag Care 2004; 10(10): 717-722.

20. Subramanian $U$, Ackermann RT, Brizendine EJ, et al. Effect of advanced access scheduling on processes and intermediate outcomes of diabetes care and utilization. J Gen Intern Med 2009; 24(3): 327-333. DOI: https://doi. org/10.1007/s11606-008-0888-2

21. Pedersen CB. The Danish Civil Registration System. Scand J Public Health 2011; 39(7 Suppl): 22-25. DOI: https:// doi.org/10.1177/1403494810387965

22. Andersen JS, Olivarius NDF, Krasnik A. The Danish National Health Service Register. Scand J Public Health 2011; 39(7 Suppl): 34-37. DOI: https://doi.org/10.1177/1403494810394718

23. Kjaersgaard $M$, Vedsted $P$, Parner $E$, et al. Algorithm linking patients and general practice in Denmark using the Danish National Health Service Register. Clin Epidemiol 2016; 8: 273-283. DOI: https://doi.org/10.2147/CLEP. S108307

24. Statistics Denmark. The Danish system for access to micro data. Copenhagen: Statistics Denmark; 2012.

25. Charlson ME, Pompei P, Ales KL, MacKenzie CR. A new method of classifying prognostic comorbidity in longitudinal studies: development and validation. J Chronic Dis 1987; 40(5): 373-383. DOI: https://doi.org/10. 1016/0021-9681(87)90171-8

26. Lynge E, Sandegaard JL, Rebolj M. The Danish national patient register. Scand J Public Health 2011; 39 (7 Suppl): 30-33. DOI: https://doi.org/10.1177/1403494811401482

27. Gjerstorff ML. The Danish cancer registry. Scand J Public Health 2011; 39(7 Suppl): 42-45. DOI: https://doi.org/10. $1177 / 1403494810393562$

28. Gladstone J, Howard M. Effect of advanced access scheduling on chronic health care in a Canadian practice. Can Fam Physician 2011; 57(1): e21-25.

29. Flarup L, Moth G, Christensen MB. [The Danish out-of-hours service in an international perspective] Den danske lægevagt i internationalt perspektiv (in Danish). 2010; https://ph.au.dk/fileadmin/www.folkesundhed.au.dk/ forskningsenheden_for_almen_praksis/publikationer/udgivelser/rapporter/Den_danske_laegevagt_ISBN_978-8790004-11-8_MARTS_2010.pdf (accessed 14 Jul 2020).

30. Bankart MJG, Baker R, Rashid A, et al. Characteristics of general practices associated with emergency admission rates to hospital: a cross-sectional study. Emerg Med J 2011; 28(7): 558-563. DOI: https://doi.org/10.1136/emj. 2010.108548

31. Smits M, Peters $Y$, Broers $S$, et al. Association between general practice characteristics and use of out-of-hours GP cooperatives. BMC Fam Pract 2015; 16: 52. DOI: https://doi.org/10.1186/s12875-015-0266-1

32. Kelly SJ, Piercy H, Ibbotson R, Fowler Davis SV. Who attends out-of-hours general practice appointments? Analysis of a patient cohort accessing new out-of-hours units. BMJ Open 2018; 8(6): e020308-7. DOI: https://doi.org/10. 1136/bmjopen-2017-020308

33. Goodall S, Montgomery A, Banks J, et al. Implementation of advanced access in general practice: postal survey of practices. Br J Gen Pract 2006; 56(533): 918-923.

34. Abou Malham S, Touati N, Maillet L, Breton M. The challenges of implementing advanced access for residents in family medicine in Quebec. do promising strategies exist? Med Educ Online 2018; 23(1): 1438719. DOI: https:// doi.org/10.1080/10872981.2018.1438719

35. Kiran T, O'Brien P. Challenge of same-day access in primary care. Can Fam Physician 2015; 61(5): 399-400.

36. Salisbury C, Sampson F, Ridd M, Montgomery AA. How should continuity of care in primary health care be assessed? Br J Gen Pract 2009; 59(561): e134-e141. DOI: https://doi.org/10.3399/bjgp09X420257

37. Weir SS, Page C, Newton WP. Continuity and access in an academic family medicine center. Fam Med 2016; 48(2): 100-107.

38. Oliver D, Deal K, Howard M, et al. Patient trade-offs between continuity and access in primary care interprofessional teaching clinics in Canada: a cross-sectional survey using discrete choice experiment. BMJ Open 2019; 9(3): e023578. DOI: https://doi.org/10.1136/bmjopen-2018-023578

39. Sampson F, Pickin M, O'Cathain A, et al. Impact of same-day appointments on patient satisfaction with general practice appointment systems. Br J Gen Pract 2008; 58(554): 641-643. DOI: https://doi.org/10.3399/ bjgp08X330780

40. Finkelstein SR, Liu N, Rosenthal D, Poghosyan L. When open access might not work: understanding patient attitudes in appointment scheduling. Health Care Manage Rev 2018; 43(4): 348-358. DOI: https://doi.org/10.1097/ HMR. 0000000000000150 
41. Penchansky R, Thomas JW. The concept of access: definition and relationship to consumer satisfaction. Med Care 1981; 19(2): 127-140. DOI: https://doi.org/10.1097/00005650-198102000-00001

42. Aday LA, Andersen R. A framework for the study of access to medical care. Health Serv Res 1974; 9(3): 208-220. 